\title{
Fetal Immatür Servikal Teratom Olgu Sunumu: Prenatal Tanı ve Yönetim
}

\author{
A Case Report of Fetal Immature Cervical Teratoma: \\ Prenatal Diagnosis and Management
}

\section{Erkan Çağlıyan $\oplus$, Süreyya Sarıdaș Demir $\oplus$, Samican Özmen $\odot$, Alper Mankan $\oplus$, Mustafa Olguner $\odot$ Haluk Vayvada $\oplus$, Taner Erdağ $\odot$}

Cite as: Çağlıyan E, Sarıdaş Demir S, Özmen S, et al. Fetal immatür servikal teratom olgu sunumu: Prenatal tanı ve yönetim. Forbes J Med. 2020;1(1):18-22.

öz

Teratomlar her üç germ yaprağından köken alan ve en sık sakrokoksigeal bölge yerleşim gösteren tümöral lezyonlardır. Baş ve boyunda görülen teratomlar fetal dönemde görülen teratomların yaklaşık \%6'sını oluşturmaktadır. Servikal bölgede yer alan teratomlar ciddi solunum sıkıntısı ve mortalite riski tașırlar. Üst solunum yolları ile ilișkinin kesin olarak değerlendirildiği prenatal tanı ve multidisipliner yaklaşımla bu riskler azaltılabilir. Bu olgu sunumunda, prenatal dönemde servikal teratom tanısı alan ve post-natal dönemde merkezimizde opere edilen olgu literatür eşliğinde sunulmuştur

Anahtar kelimeler: Cerrahi, EXіT prosedürü, servikal teratom, prenatal tanı

\section{ABSTRACT}

Teratomas are tumoral lesions that originate from three germ layers and are most commonly located in the sacrococcygeal region of the fetal body. Teratomas in the head and neck account for $6 \%$ of all teratomas seen during fetal life. Cervical teratomas carry the risk of serious respiratory distress, and mortality. These risks can be reduced with prenatal diagnosis where this relationship is evaluated and multidisciplinary approach In this case report, we present a patient with large cervical teratoma diagnosed prenatally and undergone surgery in postnatal period in our hospital with a review of the literature.

Keywords: Surgery, EXIT procedure, cervical teratoma, prenatal diagnosis
Received/Gelis: 25.10 .2020

Accepted/Kabul: 29.10.2020

Publication date: 09.11.2020

Erkan Çağlıyan

Dokuz Eylül Üniversitesi Tıp Fakültesi, Kadın Hastalıkları ve Doğum Anabilim Dalı, İzmir - Türkiye

drerkan.cagliyan@gmail.com ORCID: 0000-0001-6864-6551

S. Sandaş Demir 0000-0002-4051-3703

S. Özmen 0000-0001-6050-4110

A. Mankan 0000-0001-5822-403X Dokuz Eylül Üniversitesi Tıp Fakültesi, Kadın Hastalıkları ve Doğum Anabilim Dalı, İzmir, Türkiye

M. Olguner 0000-0003-3610-6598 Dokuz Eylül Üniversitesi Tıp Fakültesi, Çocuk Cerrahisi Anabilim Dalı, İzmir, Türkiye

H. Vayvada 0000-0002-4493-8805 Dokuz Eylül Üniversitesi Tıp Fakültesi, Plastik ve Rekontruktif Cerrahi Anabilim Dalı, İzmir, Türkiye

T. Erdă 0000-0001-5636-3343 Dokuz Eylül Üniversitesi Tıp Fakültesi, Kulak-Burun-Boğaz Hastalıkları Anabilim Dalı, İzmir, Türkiye 


\section{Giriș}

Konjenital teratomlar, çocukluk çağında görülen tüm neoplazilerin \%0,1'inden daha azını oluşturan, her üç germ yaprağından köken alan nadir tümörler olup, en sık yerleşim yerleri sakrokoksigeal alandır. ${ }^{1}$ Konjenital teratomların $\% 10$ 'dan az bir kısmı baş ve boyun yerleşimlidir. ${ }^{2}$ Histolojik olarak benign tümörler olmakla birlikte, büyük çaplara ulaşabilen servikal teratomlar yenidoğanda hava yolu obstrüksiyonuna bağlı ciddi solunum sıkıntısı ve mortalite riski taşırlar. ${ }^{3,4}$

Fetal baş ve boyun kitlesi saptanan olgularda değerlendirmede genetik anomaliler araştırılmalı, ayırıcı tanıda ensefalomyelosel, lenfanjiom/higroma, teratom, sarkom, hemanjiom, nöroblastom ve guatr akla gelmelidir. ${ }^{5}$ Ultrasonografide kitle solid, kistik veya mikst görünümde olabilir, kitlede vaskülarizasyon, septasyon, kalsifikasyon izlenebilir, unilateral veya bilateral olabilir. ${ }^{\circ}$

Teratomlu olgularda fetusun amniyotik siviyı yutmasının bozulmadan dolayı polihidramnios gözlenebilir. Bununla birlikte, trakeal basıya bağlı acil neonatal solunum sıkıntısı mortalitenin en sık nedenidir. ${ }^{6,7}$ Detaylı değerlendirme ve takipte görüntüleme yöntemlerinin daha yaygın ve etkin olarak kullanılması sonucunda artan prenatal tanı oranları, konjenital teratomu olan bebeklerde doğum sonrası sonuçları önemli ölçüde iyileştirmiş̧ir. ${ }^{8}$

\section{OLGU}

Yirmi beş yaşında nullipar, 30 hafta 2 gün gebeliği olan hasta dış merkezde yapılan fetal MR sonucunda boyunda kitlesel lezyon saptanması üzerine perinataloji kliniğimize yönlendirildi. MR görüntülemede sol prefrontal bölge ve boyunda 27x19 mm çaplı, kistik alanlar içeren kitlesel lezyon ayırt edildiği, bunun yanında fetal üst sağ yarımda 58x46 mm boyutlu, internal septasyonlar içeren 3-4 kompartmanlı geniş bir kistik lezyon izlendiği belirlendi. Ultrasonografide sol servikal bölgeden köken aldığı düşünülen yaklaşı 100x70 mm boyutunda septasyonlar içeren kistik kitlesel lezyon izlendi (Resim 1a,b). Polihidramnios ve fetal hidrops bulguları saptanmadı. Umblikal arter ve MCA Doppler normal sınırlarda izlendi. Fetal boyundaki kitlesel lezyon nedeniyle gelişebilecek obstetrik sorunlar nedeniyle haftalık izleme alınan hasta 346 gebelik haftasında erken membran rüptürü gelişmesi üzerine başvurdu. Boyundaki kitle lezyonunun vaginal doğuma engel olabileceği, kitle basısı nedeniyle yenidoğanda solunum sıkıntısı ve entubasyon zorluğu yaşanabileceği düşünülerek EXIT (Ex utero Intrapartum Treatment Procedure) hazırlıkları yapılarak sezaryen doğum planlandı. Sezaryen sırasında EXIT prosedürü gerekliliği olasılığına karşın çocuk cerrahisi, yenidoğan bölümü doktorları doğum salonunda hazır bulundu. Yenidoğan entübasyonunun kitle basısı nedeniyle yapılamaması durumunda acil trakeostomi
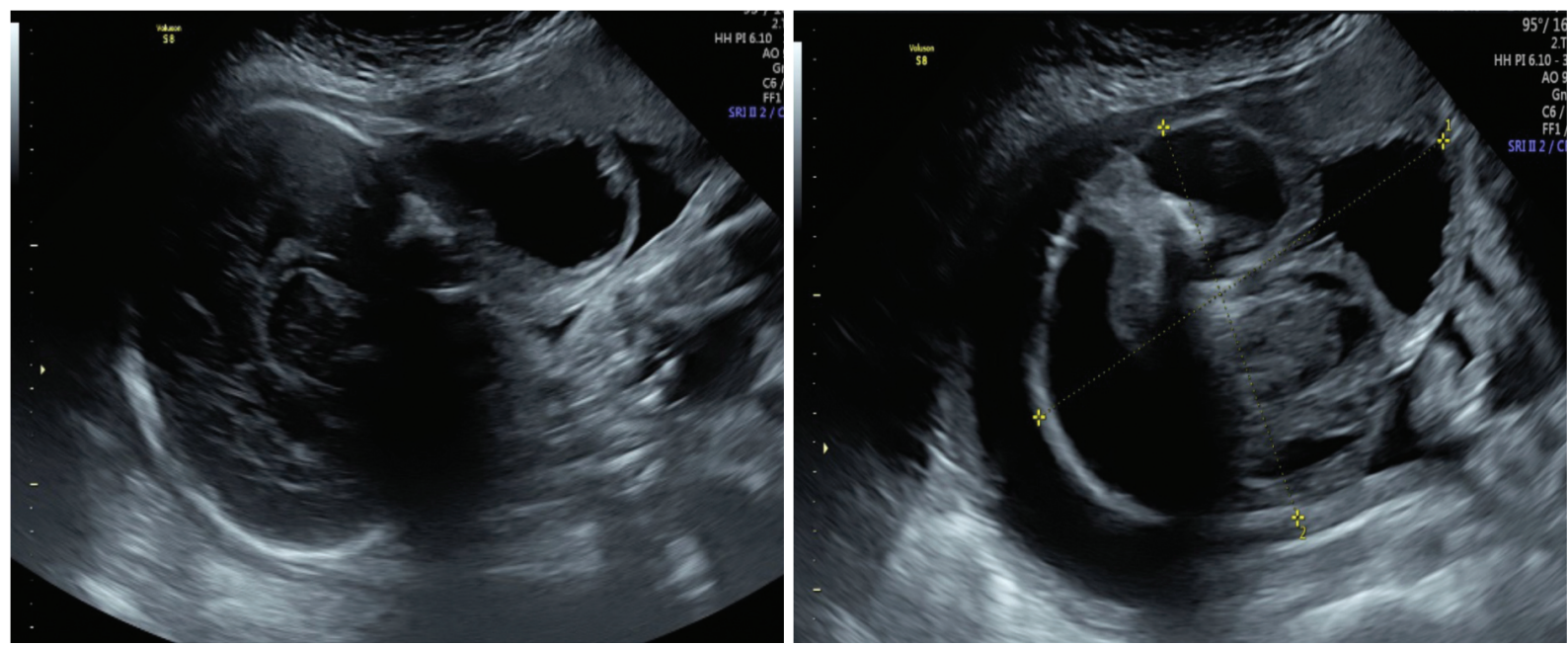

Resim 1a,b. Otuzuncu gebelik haftasındaki fetal boynun sol antero-lateralinden köken alan kistik-solid alanlar içeren servikal teratom, gri-skala görüntüsü. 

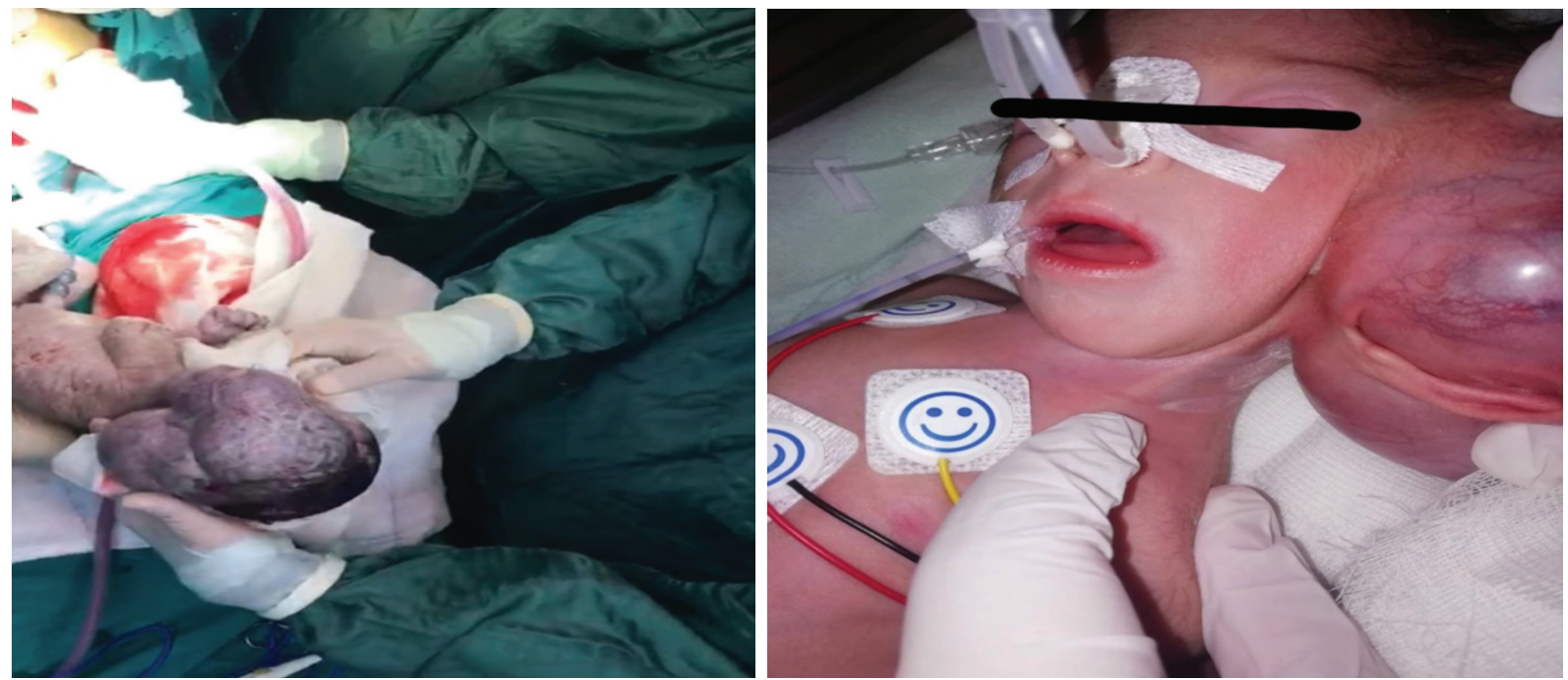

Resim 2a,b. Konjenital servikal teratom doğum sonrası görüntüsü.

açılması olasıllığına karşı KBB hastalıklarından (kulak-burun-boğaz) bir uzman yenidoğan uzmanına eşlik etti. Sezaryen ile baş geliş 2,343 g canlı kız bebek boyundaki kitleye zarar verilmeden doğurtuldu (Resim 2a,b).

Bebek doğumdan hemen sonra yenidoğan hekimi tarafindan değerlendirildi. APGAR skoru sıraslyla (1. ve 5. dk.) 2-8 olan bebeğin spontan solunumu olması üzerine entübasyon ve trakeostomiye gerek görülmedi, 1 . düzey yoğun bakıma yatırılarak takip edildi. Postpartum 1. günde görülen serum AFP düzeyi $138878.50 \mathrm{ng} / \mathrm{ml}$ olarak saptandı. Doğum sonrası 6. günde bebek KBB ve plastik cerrahi bölümü doktorları tarafından opere edildi. Operasyon sırasında boyundaki $12 \mathrm{~cm}$ boyutundaki dev kitle intakt olarak eksize edildi. KBB tarafından mastoid kavitedeki $2 \mathrm{~cm}$ boyutundaki kist eksize edildi. Kitlenin patolojik incelemesinde grade 3 immatür teratom, mastoid kavitedeki kitle matür teratom ile uyumlu olarak raporlandı. Post-operatif 7. günde serum AFP düzeyinin $61,389,60 \mathrm{ng} / \mathrm{ml}$ 'ye gerilediği görüldü. Takiplerinde komplikasyon gelişmeyen, vital bulguları stabil olan bebek düzenli olarak çocuk cerrahisi, kulak-burun-boğaz ve pediatri poliklinik kontrolleri önerilerek eksterne edildi. Olgunun bilime katkı sağlayacağı konusunda aile bilgilendirilerek yayınlanması konusunda yazılımı onam alındı.

\section{TARTIŞMA}

Prenatal dönemde ultrason görüntülemenin yaygınlaşması fetal anomalilerin antenatal dönemde daha sık tanınmasına olanak sağlamaktadır. Ultrasonografi ile saptanan fetal kitle lezyonlarında ise MRI (Manyetik Rezonans Görüntüleme) antenatal tanının doğrulanması, lezyonun diğer fetal yapılarla ilişkisinin değerlendirilmesi ve postnatal tedavinin planlanmasında büyük önem taşımaktadır. ${ }^{9}$

Fetal dönemde servikal teratomlar ultrasonografide genellikle boynun antero-lateralinden köken alan, içerisinde kalsifikasyon odakları izlenen, büyük boyutlara ulaşabilen, genellikle solid veya solid-kistik alanlar barındıran multiloküle kitleler olarak izlenirler. ${ }^{8,10}$ Sıklıkla çevre yapıları içeren uzanımlar gösterirler. Süperiorda mastoid kemiğe, inferiorda klavikula ve mediastene uzanım gösterebilirler. Kalsifikasyonlar teratomlar için tanısal olmakla birlikte, olguların \%20'inden azında rastlanır. Fetal servikal kitle lezyonların ayırıcı tanısında kistik higroma, fetal guatr ve fetal boyundan köken alan yumuşak doku tümörleri düşünülmelidir. Ösefagial bası yapan kitlelere polihidramnios sıklıkla eşlik eder. Bu olgularda polihidramnios gelişmesi trakeal basının dolaylı bir kanıtı olması açısından önemlidir. ${ }^{11,12}$ Fetal MRI, kitle sınırlarının diğer fetal yapılarla olan ilişkisinin gösterilmesinde ve özellikle trakea basısı- 


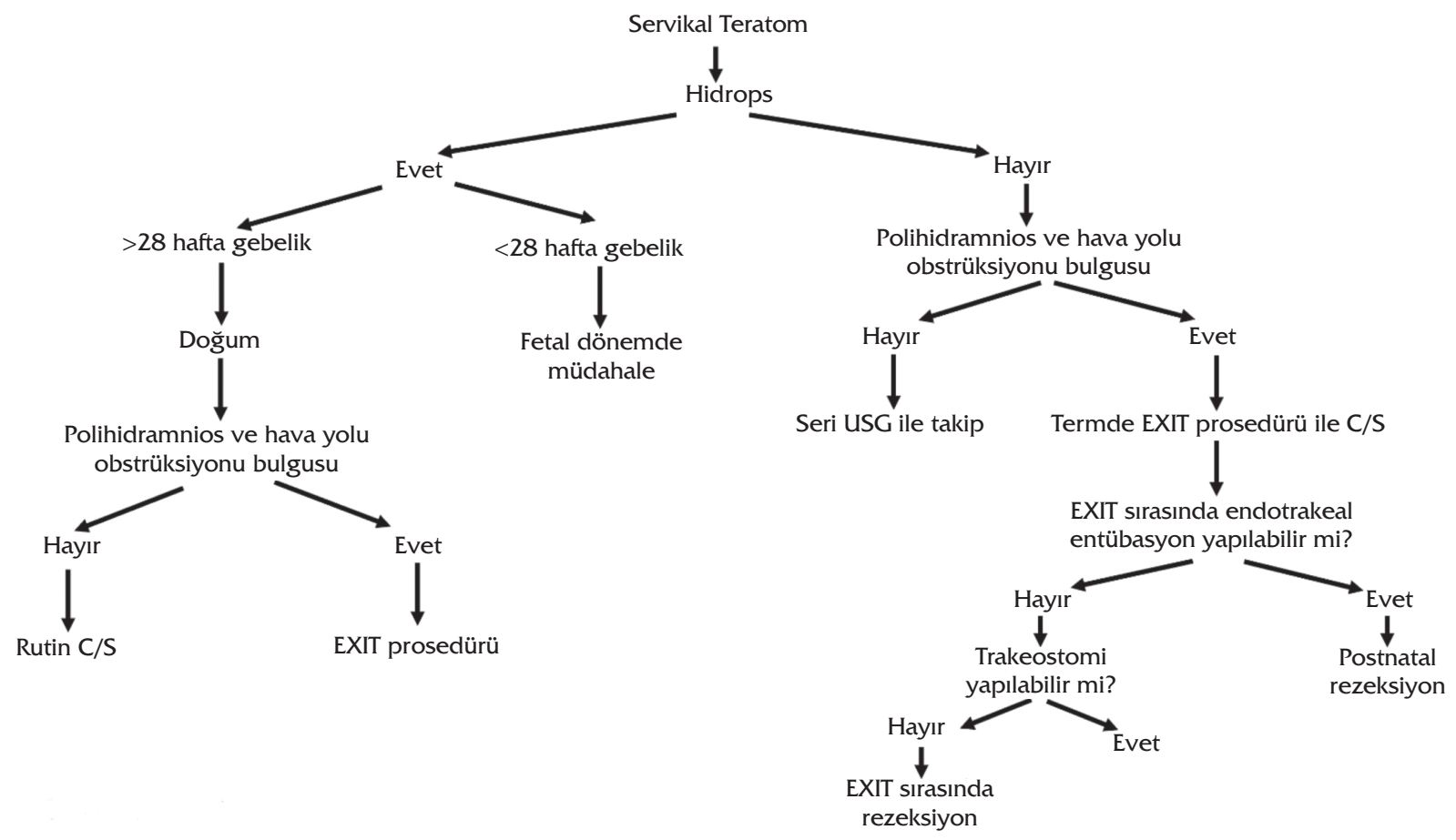

Tablo 1. Fetal servikal teratom olgularında yönetim algoritması.

nın değerlendirilmesinde önerilen görüntüleme yöntemidir. ${ }^{13}$

Fetal teratom olgularında gelişebilecek diğer bir obstetrik sorun kardiyak yetmezlik ve hidropstur. Non-immün hidrops gelişimi ani fetal ölüm riskinde ciddi artışla ilişkilidir. ${ }^{14}$ Hidrops veya başka obstetrik sorun gelişmeyen olgularda gebelik seri sonogramlarla terme kadar takip edilebilir. Bu olguda ise takiplerde polihidramnios veya fetal hidrops bulgusu gelişmedi, ancak 34 . gebelik haftasında spontan membran rüptürü nedeniyle doğum geç preterm dönemde gerçekleştirldi.

Doğum sonrası yenidoğanda kitle basısına bağlı hava yolu obstrüksiyonu servikal teratomun en ciddi postnatal komplikasyonudur. Baş-boyun teratom olgularında mortalite oranı \%23 olarak bildirilmiştir. Bu nedenle doğumunun gerektiğinde EXIST prosedürü uygulayabilecek donanıma sahip merkezlerde planlanması önerilmektedir. ${ }^{15}$ EXIT prosedürü fetüsün parsiyel olarak doğumunun ardından fetal-plasental ünite işlevsel iken, kord akımı kesilmeden önce yenidoğana yapılan girişimleri gösterir. ${ }^{15,16}$ EXIT, hava yoluna bası oluşturabilecek fetal anomalilerin varlı̆̆ında fetal oksijenizasyon bozulmadan endotrakeal entübasyon veya trakeostomi açılmasına olanak sağlar ${ }^{15}$ (Tablo 1).

Konjenital servikal teratomlarda kitenin tamamının cerrahi olarak eksizyonu en uygun tedavi şeklidir. Özellikle immatür teratomlarda kitlenin tam ve başarılı bir şekilde eksizyonu nüksleri engellemek açısından önemlidir. ${ }^{17}$ Bu olgada da kitle çevre dokudan tamamen ayrılarak total olarak eksize edildi. Post-operatif dönemde yenidoğanda solunum sorunları, yutma güçlüğü, nörolojik sekeller bulgusu saptanmadı.

Sonuç olarak, konjenital servikal teratomlar nadir görülen fetal tümöral lezyonlardır. Prenatal tanı, doğumun uygun koşullarda planlanması ve multidisipliner yaklaşım yenidoğan açısından yaşamsal öneme sahiptir.

Çıkar Çatışması: Yoktur.

Hasta Onamı: Alındı.

Conflict of Interest: None.

Informed Consent: Receipt. 


\section{KAYNAKLAR}

1. Cattle LD, De Backer A, Goossens A. Teratoma, neck. Sono World. 1992;01:15-20.

2. Elmasalme F, Giacomantonio M, Clarke KD, Othman E, Matbouli S. Congenital cervical teratoma in neonates. Case report review. Eur J Pediatr Surg. 2000;10(4):252-7. doi.org/10.1055/s- 2008 1072369

3. Johnson N, Shah PS, Shannon P, Campisi P, Windrim R. A Challenging Delivery by EXIT Procedure of a Fetus With a Giant Cervical Teratoma. J Obstet Gynaecol Canada. 2009;31(3):267-71. doi. org/10.1016/S1701-2163(16)34126-3

4. Arslan G, Daloğlu FT, Ağtaş Ö. Yenidoğanda Servikal İmmatür Teratom: Olgu Sunumu. Vol 2. Accessed October 4, 2020. www.tcpdf.org

5. Güzelmansur I, Aksoy HT, Hakverdi S, Seven M, Dilmen U, Dilmen G. Fetal cervical neuroblastoma: Prenatal diagnosis. Case Rep Med. 2011;2011. doi.org/10.1155/2011/529749

6. Rempen A, Feige A. Differential diagnosis of sonographically detected tumours in the fetal cervical region. Eur J Obstet Gynecol Reprod Biol. $1985 ; 20(2): 89-105$. doi.org/10.1016/00282243(85)90122-4

7. Silberman R, Mendelson IR. Teratoma of the neck: Report of two cases and review of the literature. Arch Dis Child. 1960;35(180):159-70. doi. org/10.1136/adc.35.180.159

8. Thawani J, Randazzo M, Singh N, Pisapia J, Abdullah K, Storm P. Management of Giant Cervical Teratoma with Intracranial Extension Diagnosed in Utero. J Neurol Surg Reports. 2016;77(03):e118-e20. doi. org/10.1055/s-0036-1586211

9. Hasiotou M, Vakaki M, Pitsoulakis G, et al. Congenital cervical teratomas. Int J Pediatr Otorhinolaryngol.
2004;68(9):1133-9. doi.org/10.1016/j. ijporl.2004.04.018

10. Pantalone Kevin, Jones Stephen, Weil Robert, Hamrahian Amir. MRI Atlas of Pituitary Pathology. 2015. doi.org/10.1016/B978-0-12-8025772.00001-3

11. Jordan RB, Gauderer MWL. Cervical teratomas: An analysis. Literature review and proposed classification. J Pediatr Surg. 1988;23(6):583-91. doi. org/10.1016/S0022-3468(88)80373-7

12. Güngör S, Ercan CM, Başer İ, Ceyhan ST, Demirbağ S. Konjenital Servikal Teratom; Prenatal Tanı ve Yaklaşım. Türkiye Klin J Gynecol Obs. 2005;15:321-4.

13. Coakley F V. Role of magnetic resonance imaging in fetal surgery. Top Magn Reson Imaging. 2001;12(1):39-51. doi.org/10.1097/00002142200102000-00005

14. Hutchison AA, Drew JH, Yu VY. Nonimmunologic hydrops fetalis: A review of 61 cases. Obstet Gynecol. 1982;59:347-52.

15. Hirose S, Sydorak RM, Tsao K, et al. Spectrum of intrapartum management strategies for giant fetal cervical teratoma. In: Journal of Pediatric Surgery. Vol 38. W.B. Saunders; 2003:446-50. doi. org/10.1053/jpsu.2003.50077

16. Mychaliska GB, Bealer JF, Graf JL, Rosen MA, Adzick NS, Harrison MR. Operating on placental support: The ex utero intrapartum treatment procedure. In: Journal of Pediatric Surgery. Vol 32. W.B. Saunders; 1997:227-31. doi.org/10.1016/S00223468(97)90184-6

17. Kerner B, Flaum E, Mathews H, et al. Cervical teratoma: Prenatal diagnosis and long-term follow-up. Prenat Diagn. 1998;18(1):51-9. doi.org/10.1002/ (SICI) $1097-0223$ (199801) 18:1<51:: AID PD220>3.0.CO;2-U 